\title{
Neurochemical Substrates and Neuroanatomical Generators of the Event-Related P300
}

\author{
Thomas Frodl-Bauch Ronald Bottlender Ulrich Hegerl \\ Department of Clinical Neurophysiology and Department of Psychiatry, Ludwig-Maximilians-Universität München, \\ Deutschland
}

\section{Key Words}

Event-related potentials · P3b - Neurotransmitter ·

Subcomponents

\begin{abstract}
The present review focuses on the current knowledge of the neurochemical processes and neuronal structures involved in the generation of P300. The increasing knowledge in this area facilitates the physiological interpretation of $\mathrm{P} 300$ findings as well as the link between P300 research and other research findings in biological psychiatry. Concerning the question of neurochemical substrates, the glutamatergic, GABAergic, cholinergic, noradrenergic, dopaminergic and serotonergic influences on P300 are reviewed. The knowledge of the generating structures of P300 is summarized from intracranial studies, magnetoencephalographic investigations, lesion and animal studies.
\end{abstract}

\section{Introduction}

Thirty-three years have passed since Sutton et al. [1] first described long-latency positive event-related potentials (ERPs). Now commonly referred to as the P300 (also called P3, P3b or LPC), this positive ERP occurs with a latency of about $300 \mathrm{~ms}$ after meaningful task-relevant target stimuli (fig. 1). It is often elicited with a simple discrimination task, the 'oddball paradigm'. In this paradigm, two different stimuli are presented, with task-relevant target stimuli occurring less frequently than the nontarget or standard stimuli (e.g. with probabilities 0.20 and 0.80 , respectively). The subject's task can be, for example, to press a button or to silently count the task-relevant stimuli which are presented in auditory, visual, somatosensory or olfactory modalities.

In the following years, P300 was studied extensively with different methods and paradigms. Most of these studies focused on the relationship between P300 and psychological principally cognitive aspects. Major theoretical interpretations of $\mathrm{P} 300$ amplitude are that it indexes the updating of the working memory [2], or that it reflects context closure [3]. Considering experimental conditions, P300 amplitude is related to stimulus proba-

T. Frodl-Bauch

Department of Psychiatry, Department of Clinical Neurophysiology, EEG Ludwig-Maximilians-Universität München

Nussbaumstrasse 7, D-80336 Munich (Germany)

Tel. +49 895160 3409, E-Mail Thomas.Frodl-Bauch@psy.med.uni-muenchen.de 
Fig. 1. The P300 can be typically elicited with a discrimination paradigm. A task-relevant target stimulus occurs less frequently than a nontarget stimulus (e.g. with probabilities 0.20 and 0.80 , respectively). P300 is a positive ERP with a maximum at the parietocentral electrodes which occurs at about $300 \mathrm{~ms}$ after a task-relevant target stimulus when the subject has to perform a task, for example to press a button or to count the target stimuli (waveform at the bottom). After the occurrence of the nontarget stimulus no P300 is elicited (waveform at the top).

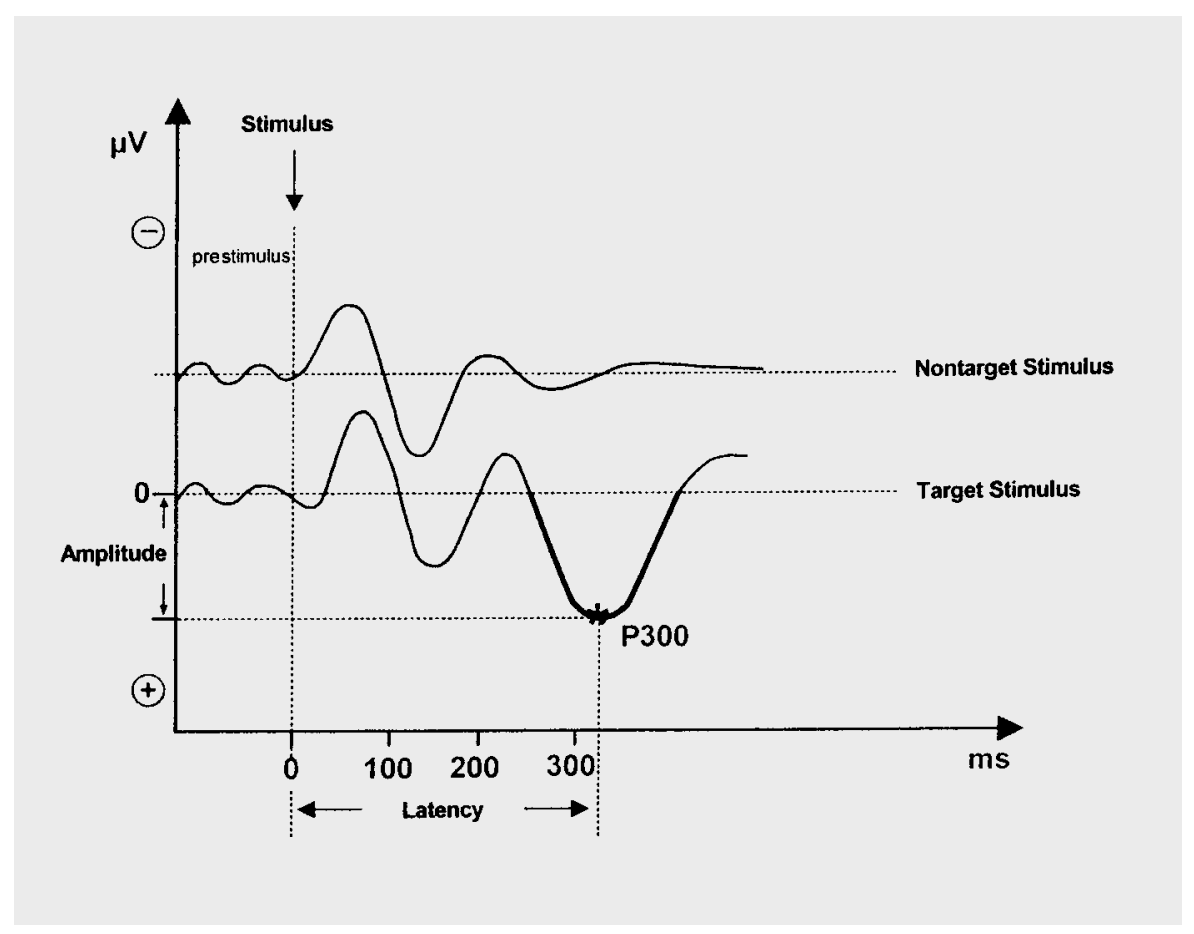

bility, stimulus significance, task difficulty, motivation and vigilance [4]. P300 latency is mainly influenced by the task complexity and is a reflection of stimulus evaluation and of response processing when response times are short under fast experimental conditions [reviewed in 5].

Alterations of P300 have been found in various psychiatric disorders. In schizophrenia, P300 amplitude reduction is one of the most robust biological findings [6, 7]. Reduced P300 amplitudes were found to predict a bad clinical outcome with antipsychotic treatment [8], incomplete remission [9] and a higher risk for tardive dyskinesia [10]. Furthermore, P300 latency was prolonged in some studies of schizophrenia [11]. In dementia, P300 amplitude reductions and latency prolongations have consistently been reported $[12,13]$. These findings raised the question whether or not $\mathrm{P} 300$ could aid in the diagnosis of dementia $[12,14]$. Moreover, P300 amplitudes were reduced in alcoholics and family members of alcoholics [15]. Furthermore, prolongations of P300 latency were reported in patients with HIV [16] and idiopathic parkinsonism [17]. In patients with depression, less consistent findings were made about P300 amplitude or latency.

The physiological interpretation of P300 data, however, has remained difficult, because among other problems, the question of its neural origin has not been solved. Knowledge of the neurochemical and neuroanatomical substrates of P300 would be important for the physiological interpretation of P300 findings and for relating P300 research to other research areas, such as neurochemical and neuroanatomical studies in psychiatry. The aim of this review is to summarize the present knowledge of the neurochemical processes and the neural structures involved in the generation of the auditory P300.

\section{Neurochemical Substrates of the P300}

The increasing knowledge of the anatomical structures and cellular processes underlying ERPs, and the methodological advances in analysis of ERPs offer a possibility to bridge the gap between ERPs and their basic neurophysiology. It is now widely accepted that ERPs result from intracortical currents induced by excitatory and inhibitory postsynaptic potentials (EPSPs, IPSPs), which are triggered by the release of neurotransmitters. Therefore, ERPs reflect postsynaptic effects of neurotransmitters like glutamate and GABA and indirect modulating effects from neuromodulators like acetylcholine, noradrenaline, dopamine or serotonine. They could become of clinical value as indicators for disturbances in these neurochemical systems. However, P300 can only be used as such an indicator when at least a certain specificity exists in the 
relationship between P300 and the different neurochemical systems. Therefore, it is necessary to characterize the role of neurotransmitters in the generation of P300.

\section{Glutamatergic Influences}

Physiological analysis and the application of the current source density method to intracortical recordings suggest that the EPSPs from the apical dendrites with sources in deeper layers near or at the soma are most likely to be responsible for slow cortical potentials [18] such as P300. The N-methyl- $D$-aspartate (NMDA) receptors, which are activated by glutamate could be of special importance. The glutamatergic system is the most important excitatory neurotransmitter system and plays an important role in the electrogenesis of P300 potentials [19]. As discussed, for example, by Javitt et al. [20], these receptors have long EPSPs of 10-100 ms, which seem to correspond to late components such as P300. Furthermore, the effect of NMDA receptor activity on ERPs has been shown in animal experiments with intracranial recordings [20]. MK-801, a high-affinity high-specificity NMDA channel blocker, was administered intracortically in a monkey. The mismatch negativity (MMN), a late cognitive ERP, was reduced after the administration of MK801. MMN precedes P300 and shares similarities with P300 because both P300 and MMN are events in the processing of stimulus deviance.

In addition, P300 and the NMDA receptor function have a remarkable similarity. Both P300 and NMDA receptor function depend on preconditions. The P300 component is elicited only after task-relevant stimuli. It is dependent on the precondition that a series of irrelevant standard stimuli has been presented when the deviating task-relevant stimuli occurs. On the other hand, potentials of NMDA receptors are blocked in a voltage-dependent fashion by $\mathrm{Mg}^{2+}$. The NMDA receptor function is dependent on the degree of membrane depolarization and, therefore, like P300, has a conditional aspect.

In summary, P300 is most likely caused by a direct excitatory postsynaptic effect of glutamatergic neurotransmission.

\section{GABAergic Influences}

GABA is the most important inhibitory neurotransmitter, and IPSPs triggered by GABAergic effects could also be responsible for late ERPs such as P300. The GABAergic transmission in the reticular nucleus of the thalamus has been suggested to contribute to positive cortical potentials via inhibitory hyperpolarization [21]. Then, indirect inhibitory influences on GABAergic IPSPs could reduce the negativity of some cortical brain regions and, therefore, could be measured as positive potentials. However, the findings from current source density methods point in another direction. It is more likely that slow cortical potentials are directly caused by EPSPs and not by IPSPs.

Another explanation of the GABAergic effects on P300 is that GABAergic influences decrease EPSPs [22] and, therefore, reduce P300. This is supported by findings which showed that sedating GABAergic drugs alter P300 parameters. P300 amplitudes were reduced [23, 24] and P300 latencies were delayed after the application of GABAergic drugs $[25,26]$.

Taken together, the present results indicate that GABAergic influences on P300 generation are most likely to be indirect. These effects on P300 could result from inhibitory influences on glutamatergic EPSPs.

\section{Cholinergic Influences}

The cholinergic neurotransmitter system has indirectly modulating effects in widely distributed neuronal networks. Acetylcholine has been found to be involved in the generation of P300 [27]. Memory performance and P300 amplitude is increased after the administration of cholinergic substances and is reduced after the administration of anticholinergic substances [28-30]. Scopolamine, an anticholinergic substance, significantly reduces the P300 amplitude and increases its latency [31, 32]. The muscarinic agonist RS 86 increases $\mathrm{P} 300$ amplitudes in patients with Alzheimer's disease [33].

Furthermore, animal studies investigating the influence of the septal cholinergic system on P300 [34, 35] found that septal cholinergic system lesions affect P300 in cats. The septal nuclei provide the major cholinergic input to the hippocampus (from the diagonal band of Broca and the medial septal nuclei) and to the neocortex (from the nucleus basalis of Meynert). However, it is not clear to what extend findings from animal studies can be generalized to explain neurochemical processes in humans.

In summary, the cholinergic system is an important neuromodulator of the $\mathrm{P} 300$-evoked potentials.

\section{Noradrenergic Influences}

Another important neuromodulator is noradrenaline. The results on the influences of noradrenergic substances on P300 are inconsistent. Findings on the influence of the substances clonidine, methylphenidate and $D$-amphetamine are difficult to interpret because these substances have not only adrenergic, but also dopaminergic, seroton- 
ergic or cholinergic activity. Clonidine, an alpha-2 adrenergic agonist, which reduces the firing rate of the locus ceruleus, slowed P300 latency and decreased P300 amplitude [36-38]. However, clonidine may produce anticholinergic effects which influence P300 per se [39]. Methylphenidate enhanced P300 amplitude in attention-deficit hyperactivity disorder children [40]. On the other hand, methylphenidate and $D$-amphetamine have also been found to not affect P300 [41, 42]. Therefore, further investigations are necessary to define the influences of adrenergic substances on P300 in humans.

In contrast to the inconsistencies concerning findings in humans, results from animal studies suggest that the noradrenergic system has a role in P300 generation. The noradrenergic locus ceruleus system has been implicated in information processing similar to that presumed to be indexed by P300-like potentials [43]. Lesions of the noradrenergic locus ceruleus caused reductions of P300 amplitude [44]. When clonidine was administered to 6 adult monkeys during an auditory 'oddball paradigm', a significant decrease in P300-like activity was observed [45]. Moreover, microinjections of alpha-2 antagonists and agonists in the temporoparietal junction resulted in significant reductions of P300 amplitudes in monkeys [46]. A model that could explain the inconsistent findings in humans and the adrenergic effects in animals proposes that noradrenaline has, at least to some extent, an inhibitory control on GABAergic activity. This indirect effect could contribute via inhibitory hyperpolarization to positive slow cortical potentials like P300 [21, 22].

In summary, the adrenergic neuromodulator system seems to have minor influences on P300 elicited during P300 recordings in humans. Stronger noradrenergic effects on P300 have been demonstrated under experimental conditions in animal studies.

\section{Dopaminergic Influences}

Stanzione et al. [17] suggested that dopaminergic neurotransmission has a physiological role in the generation of P300. They studied P300 in idiopathic parkinsonian patients, in whom destruction of dopaminergic fibers was described, and found that P300 latency was increased before therapy. Therapy with $L$-DOPA plus benserazide reduced the prolonged latency. Taken together, the studies on patients with Parkinson's disease show prolonged P300 latencies for demented patients, whereas the results in nondemented patients concerning P300 latency and amplitude were inconsistent. Because of the influence of dementia in these studies, the disturbances in the dopaminergic system do not seem to be specific for these P300 findings. Another finding which speaks against an important role of the dopaminergic system in P300 generation is that dopaminergic fibers do not seem to be necessary for P300 because toxic lesions of these fibers do not affect the monkey P300 [47].

In summary, the dopaminergic system seems to play a minor role in the generation of $\mathrm{P} 300$ processes.

\section{Serotonergic Influences}

Effects of the serotonergic agent fenfluramine and the antiserotonergic agent methysergide on P300 have not been reported until now. A prolongation of P300 latency only appears with combinations of antiserotonergic with anticholinergic substances [48]. These findings seem to focus on the interactive role between serotonergic and cholinergic substances in EEG modulation [49].

Further investigations will be needed to evaluate the neurobiological effect of serotonergic activity on P300. To date, the serotonergic system does not seem to have a modulatory role in $\mathrm{P} 300$ generation.

\section{Summary of Findings on the Neurochemical \\ Substrates of P300}

Various neurochemical influences were found on P300 generation. A model of neurochemical influences on P300 is presented in figure 2. P300 generation is triggered by the neurotransmitter glutamate, which is the most important excitatory neurotransmitter. An important modulator of these EPSPs caused by glutamate and, therefore, of this P300 activity is the cholinergic neurotransmission, which increases P300 amplitude and decreases P300 latency. On the other hand, GABAergic influences on EPSPs reduce P300 amplitude and prolong P300 latency.

Other neuromodulator systems seem to be less important for P300 generation. They seem to have, at least to some extent, indirect influence on other neurochemical systems like the GABAergic and cholinergic system, which are important for P300 generation. Modulation of any one neurochemical system will necessarily modulate many other neurochemical systems.

This complex pattern of neurotransmitter influences can explain why P300 is altered in several psychiatric disorders. Considering the glutamate hypothesis in schizophrenia, the reduced amplitude of P300 in schizophrenics could stem from disturbances in the glutamatergic system. Reduced amplitudes and prolonged latencies of P300 in dementia could be due to alterations in the cholinergic system. 
Fig. 2. Findings about neurochemical substrates of the P300 suggest this hypothetical model of P300 generation. The glutamatergic neurotransmission directly causes the EPSPs, which are responsible for the P300 activity. These EPSPs and as a consequence the P300 are modulated both indirectly by influences of acetylcholine, enhancing P300 amplitude and decreasing P300 latency, and by influences of GABA, reducing P300 amplitude and prolonging P300 latency. The adrenergic system and with minor importance, the dopaminergic and serotonergic systems seem to have indirect influence on the indirect effects of the acetylcholinergic and GABAergic systems and, thus, have shown inconsistent findings concerning P300 in humans.

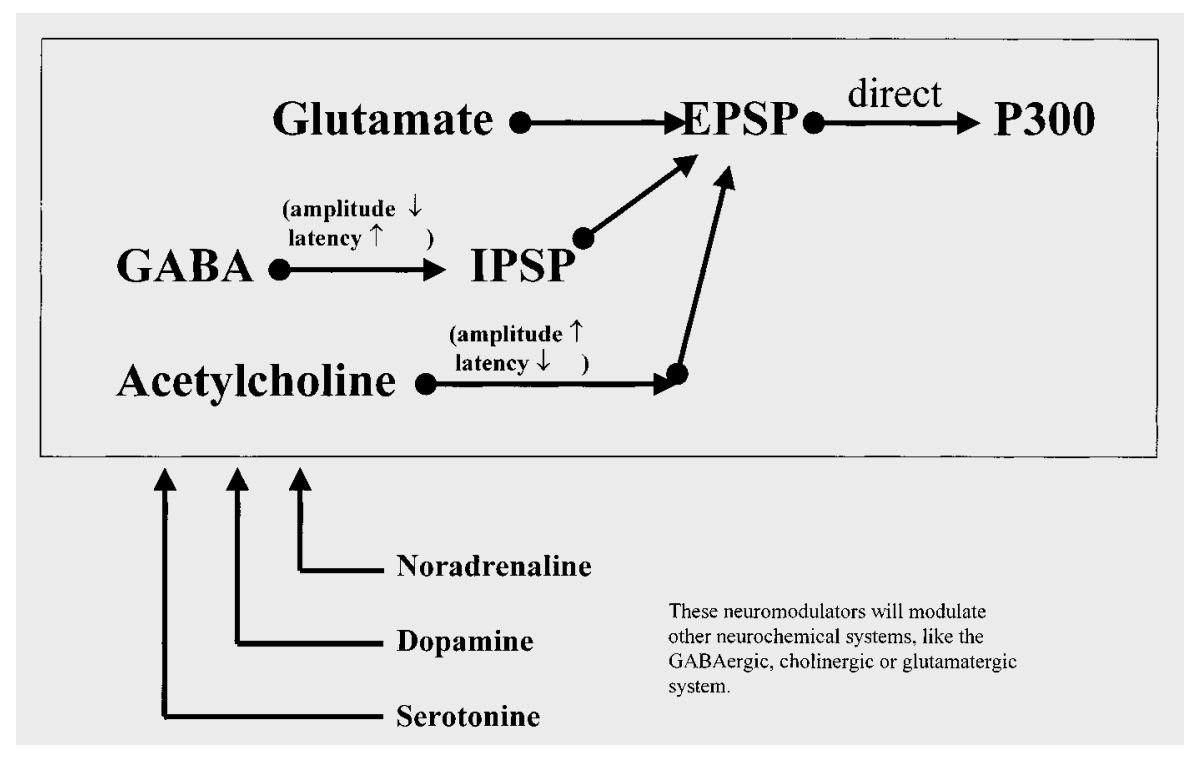

\section{Generators of P300}

In this section we will review the macroanatomical P300 generators. The distribution of the electric fields throughout the brain and at the surface of the scalp is determined by the spatial distribution of the neurons as well as by the geometry and impedance of the brain and its coverings [50]. The presupposition for summing up microfield activities and for producing a so-called 'far or open field', which is volume conducted to the surface, is that the neurons have a laminar and columnal organization. This is the case for cortical neurons. Otherwise, when microfields cancel each other, they are named 'closed fields'. Neuronal activity within closed fields will not be recorded in the scalp data.

P300 seems to be more complex than previously thought. Indeed, P300 is a composite of the activity arising from different brain generators [51]. Invasive methods, like intracranial recordings, lesion studies, lobectomy investigations and animal studies can provide evidence for the localization of $\mathrm{P} 300$ generators.

A number of studies analyzing P300 with intracranial electrodes have suggested the importance of the medial temporal lobe structures for P300 generation. Halgren et al. [52] recorded large P300 potentials from electrodes implanted in the hippocampus, parahippocampal gyrus and amygdala of epileptic patients. Okada et al. [53] and Wood et al. [54] found comparable results from studies using simultaneous scalp recordings. These results indicated a local origin of the P300 in the limbic system. Stud- ies demonstrating the broad P300 scalp distribution were consistent with a deep generator $[55,56]$.

However, the newest evidence shows that the limbic system probably has only a small influence on the generation of the scalp-recorded P300 because of several reasons:

(1) The hippocampus does not seem to produce a far field large enough to be measured at the scalp electrodes because of its special anatomy and its location deep in the temporal lobe. Deep structures, such as the hippocampus, are unlikey to be direct generators of the large $10-20 \mu \mathrm{V}$ P300-potentials recorded on the scalp [57].

(2) The studies of Paller et al. [58] presented evidence against the hippocampal generation of P300. The P300 wave was still present in monkeys with bilateral excisions to the medial temporal lobe. Arguments against these studies were that the excisions may not have affected all P300-generating structures in the temporal lobe or that other structures compensated for the disturbances.

(3) Investigations in epileptic patients after temporal lobectomies did not show any significant difference from normal subjects as to P300 [59-62]. However, the posterior hippocampus, which can produce large P300-like amplitudes [63], typically is spared in lobectomies. Thus, this argument does not exclude a far-field P300 generator in the posterior hippocampus.

(4) A patient with extensive damage to the left medial temporal lobe caused by an infiltrating glioma did not have changed $\mathrm{P} 300$ parameters [64]. 
(5) Recent investigations with intracranial electrode recordings have provided the best knowledge of $\mathrm{P} 300$ generators $[65,66]$. It was concluded that the strong voltage gradients of hippocampal activity make a direct participation of this structure in the production of P300 scalp potentials unlikely.

P300 activity was observed with intracranial electrodes in multiple sites of the temporal and parietal cortices. These structures were the posterior and superior parietal cortices [65, 66], the parietooccipital cortex [67], the inferior parietal lobule [68], the marginal gyrus [69], the sulcus temporalis superior $[65,66]$ and the posterior cingulate gyrus [66]. These findings are supported by lesion studies. Yamaguchi and Knight [70] found reduced P300 in patients with temporoparietal lesions, and Verleger [71] replicated this finding. Yamaguchi and Knight [70] also reported that unilateral damage to the temporoparietal cortex decreases P300 over both hemispheres. Therefore, the integrity of the temporoparietal junction seems to be necessary for P300 generation.

Furthermore, correlations of magnetic resonance imaging with P300 amplitudes [72] raise the possibility that the temporoparietal cortices are important areas for modulating and triggering P300. Direct evidence for a relationship between cortical abnormalities and reduced P300 comes from McCarley et al. [73]. This research group found that temporal lobe tissue loss in schizophrenics correlated significantly with changes in P300.

Moreover, animal studies reporting local microinjections of noradrenaline agonists and antagonists [46] in the temporoparietal cortices of monkeys and observations of single-unit activity in these cortices during discrimination tasks in monkeys have indicated that these cortices are generators of late positive $\mathrm{P} 300$ activity $[74,75]$.

In summary, P300 seems to be generated directly in widespread cortical areas of the temporoparietal junction and in the parietal cortices. Nevertheless, some indirect influences of subcortical structures, like the limbic system, have to be considered in explanations of P300 generation. These conclusions are in line with the reduced P300 amplitudes in patients with dementia of the Alzheimer type, who show volume loss in the temporoparietal cortical areas.

\section{P300 Subcomponents}

Findings from intracranial recordings, scalp data analysis and dipole source analysis suggest that various P300 subcomponents overlap at the surface scalp electrodes and produce $\mathrm{P} 300$ with a maximum at the parietocentral electrodes. The consequence is that functionally different physiological processes overlap and are difficult to investigate. A methodological advance is the dipole source model of P300, which is able to separate two P300 subcomponents directly from the surface scalp data [76]. These are a temporoparietal subcomponent, which seems to correspond to the parietally recorded P300, and a temporofrontal P300 subcomponent, which might correspond to the frontally recorded $\mathrm{P} 300$.

Moreover, with intracranial recordings, multiple generators were suggested for the various P300 subcomponents. Nevertheless, it remains unclear which of these structures are far-field generators and are volume conducted to the surface, and which are so-called closed-field generators whose effects are locally restricted.

With intracranial recordings, three different waveforms can be observed in several brain sites $[65,66]$. These waveforms are modality-specific auditory P300, $\mathrm{N} 2 / \mathrm{P} 3 \mathrm{a} / \mathrm{SW}$ components and $\mathrm{P} 3 \mathrm{~b}$ components, reflecting different physiological processes [77, 78]. P3b, which is generally regarded as the main component of P300, has a maximum at parietocentral electrode sites, whereas $\mathrm{P} 3 \mathrm{a}$ is located over the frontal cortex and appears especially after nontarget or novel stimuli. The slow wave has been described as 'negative-going' over frontal areas and 'positive-going' over parietal areas [77, 79, 80].

$\mathrm{P} 3 \mathrm{~b}$ is the most prominent $\mathrm{P} 300$ subcomponent. Additionally, a modality-specific auditory P300 generator has recently been found with intracranial recordings in the dorsal superior temporal plane, especially when the nontargets were subtracted from the targets $[65,66]$. With magnetoencephalographic recordings, the temporal plane has been shown to play an important role in P300 generation [81]. Moreover, N2/P3a/SW components have been observed in several diffusely distributed brain structures. These triphasic waveforms have been found in the orbitofrontal cortex, the anterior and posterior cingulate cortices, the supramarginal gyrus and in some sites of the temporal cortices [65, 66, 68, 82-84]. The prefrontal cortex, which is thought to carry out some major integrative functions, involving sensory as well as motoric and autonomic processes [85], might play a role in the generation of this P3a because P3a was significantly diminished in both hemispheres after unilateral damage to the prefrontal cortex [86].

\section{Summary of the Findings on P300 Generators}

The P300 generators are localized in multiple cortical areas. $\mathrm{P} 300$, also named $\mathrm{P} 3 \mathrm{~b}$, seems to be generated in the 
parietal cortical areas and the temporoparietal cortices. This component is most prominent in scalp data analysis with a maximum over the parietocentral electrodes. Moreover, to what extent other distinct waveforms can be measured by the surface electrodes is unclear. N2/P3a/ $\mathrm{SW}$ waveforms seem to be elicited in multiple sites of the frontal, temporal and parietal cortices. In auditory paradigms, a modality-specific P3aud. seems to originate from the superior temporal plane.

\section{Conclusion}

With respect to the neurochemical substrates and neuroanatomical generators of $\mathrm{P} 300$, there appears to be a direct triggering by glutamatergic neurotransmission in the temporoparietal junction, the parietal cortical areas and, less evident, in the medial temporal lobe structures. However, the activity of the medial temporal lobe structures does not seem to be volume conducted to the surface and to have only little influence on the generation of the scalp-recorded P300. This P300 activity is modulated indirectly by cholinergic influences, enhancing P300 amplitudes and decreasing P300 latencies, and by GABAergic influences, reducing P300 amplitudes and prolonging P300 latencies. The adrenergic, dopaminergic and serotonergic systems seem to be less important and to have more indirect influence on other neurochemical systems affecting P300, such as those of GABA and acetylcholine.

Recently, intracranial recordings and subcomponent analysis have shown that $\mathrm{P} 300$ is composed of subcomponents (P3b, P3a, SW, modality-specific auditory P300) which have different scalp distributions, different underlying neural generators and are modulated by different neurochemical processes. In addition to this P $3 \mathrm{~b}$ component, a modality-dependent auditory P300 generator has been observed on the temporal plane of the gyrus temporalis superior and diffuse $\mathrm{P} 3 \mathrm{a} / \mathrm{SW}$ generators have been found in multiple areas of the frontal, temporal and parietal cortices. However, it remains unclear which of these generators contribute to the surface P3a. Further studies are necessary to identify these underlying generators and, in particular, their neurochemical substrates.

\section{References}

1 Sutton S, Braren M, Zubin J: Evoked potential correlates of stimulus uncertainty. Science 1965;150:1187-1188.

2 Donchin E: Surprise! ... Surprise? Psychophysiology 1981;18:493-513.

3 Verleger R: Event-related potentials and cognition: A critique of the context updating hypothesis and an alternative interpretation of P3. Behav Brain Sci 1988;11:343-356.

4 Johnson R: A triarchic model of P300 amplitude. Psychophysiology 1986;23:367-384.

5 Verleger R: On the utility of P3 latency as an index of mental chronometry. Psychophysiology 1997;34:131-156.

6 Roth WT, Pfefferbaum A, Kelly AF, Berger PA, Kopell BS: Auditory event-related potentials in schizophrenia and depression. Psychiatry Res 1981;4:199-212.

7 Frodl-Bauch T, Gallinat J, Meisenzahl EM, Möller H-J, Hegerl U: P300 subcomponents reflect different aspects of psychopathology in schizophrenia. Biol Psychiatry, in press.

8 Ford JM, White PM, Csernansky JG, Faustman WO, Roth WT, Pfefferbaum A: ERPs in schizophrenia: Effects of antipsychotic medication. Biol Psychiatry 1994;36:135-170.

9 Strik WK, Dierks T, Franzek E, Maurer K, Beckmann H: Differences in P300 amplitudes and topography between cycloid psychosis and schizophrenia in Leonhard's classification. Acta Psychiatr Scand 1993;87:179-183.
10 Hegerl U, Juckel G, Müller-Schubert A, Pietzcker A, Gaebel W: Schizophrenics with small P300: A subgroup with neurodevelopmental disturbance and high risk for tardive dyskinesia? Acta Psychiatr Scand 1995;91: 120-125.

11 Blackwood DHR, Whalley LJ, Christie JE, Blackburn IM, St Clair D, McInnes A: Changes in auditory P3 event-related potential in schizophrenia and depression. Br J Psychiatry 1987;150:154-160.

12 Pfefferbaum A, Ford JM, Kraemer HC: Clinical utility of long latency 'cognitive' eventrelated potentials (P3): The cons. Electroencephalogr Clin Neurophysiol 1990;76:6-12.

13 Ito J, Yamoa S, Fukuda H, Mimori Y, Nakamura S: The P300 event-related potentials in dementia of the Alzheimer type. Correlations between P300 and monoamine metabolites. Electroencephalogr Clin Neurophysiol 1990;77: 174-178.

14 Maurer K, Dierks T: Atlas of brain mapping topographic mapping of EEG and evoked potentials; in Maurer K, Dierks T (eds): Atlas of Brain Mapping. Berlin, Springer, 1991.

15 Porjesz B, Begleiter H: Event-related potentials in individuals at risk for alcoholism. Alcohol 1990; 7:465-469.
16 Baldeweg T, Gruzelier JH, Catalan J, Pugh K, Lovett E, Riccio M, Stygall J, Irving G, Catt S, Hawkins D: Auditory and visual event-related potentials in a controlled investigation of HIV infection. Electroencephalogr Clin Neurophysiol 1993; 88:356-368.

17 Stanzione P, Fattapposta F, Giunti P, D'Alessio C, Tagliati M, Affricano C, Amabile G: P300 variations in parkinsonian patients before and during dopaminergic monotherapy: A suggested dopamine component in P300. Electroencephalogr Clin Neurophysiol 1991;80: 446-453.

18 Mitzdorf U: Current source density method and application in cat cerebral cortex. Investigation of evoked potentials and EEG phenomena. Physiol Rev 1985;65:37-99.

19 McCarley RW, Faux SF, Shenton ME, Nestor PG, Adams J: Event-related potentials in schizophrenia: Their biological and clinical correlates and a new model of schizophrenic pathophysiology. Schizophr Res 1991;4:209231.

20 Javitt DC, Schroeder CE, Steinschneider M, Arezzo JC, Ritter W, Vaughan HG Jr: Cognitive event-related potentials in human and non-human primates: Implications for the PCP/NMDA model of schizophrenia. Electroencephalogr Clin Neurophysiol Suppl 1995; 44:161-175. 
21 Marczynski TJ: A model of brain function; in McCallum WC, Zappoli R, Denoth F (eds): Cerebral Psychophysiology: Studies in EventRelated Potentials. Amsterdam, Elsevier, 1986, pp 351-367.

22 Timsit-Berthier M: Contingent negative variation (CNV) in psychiatry; in McCallum WC, Zappoli R, Denoth F (eds): Cerebral Psychophysiology: Studies in Event-Related Potentials. Amsterdam, Elsevier 1986, pp 429-438.

23 Rockstroh B, Elbert T, Lutzenberger W, Altenmuller E: Effects of the anticonvulsant benzodiazepine clonazepam on event-related brain potentials in humans. Electroencephalogr Clin Neurophysiol 1991;78:142-149.

24 Reinsel RA, Veselis RA, Heino R, Miodownik S, Alagesan R, Bedford RF: Effect of midazolam on the auditory event-related potential: Measures of selective attention. Anesth Analg 1991;73:612-618.

25 Ray PG, Meador KJ, Loring DW: Diazepam effects on the P3 event-related potential. J Clin Psychopharmacol 1992;12:415-419.

26 Domino EF, French J, Pohorechi R, Galus CF, Pandit SK: Further observations on the effects of subhypnotic doses of midazolam in normal volunteers. Psychopharmacol Bull 1989;25: 460-465.

27 Callaway E: The pharmacology of human information processing. Psychophysiology 1983; 20:359-370.

28 Barbeau A: Emerging treatments: Replacement therapy with choline or lecithin in neurological diseases. Can J Neurol Sci 1978;5:157-160.

29 Mohs RC, Davies KL: Interaction of choline and scopalamine in human memory. Life Sci 1985;37:193-197.

30 Dierks T, Frölich L, Ihl R, Maurer R: Event related potentials and psychopharmacology. Cholinergic innervation of P300. Pharmacopsychiatry 1994;27:72-74.

31 Hammond EJ, Meador KJ, Aung-Din R, Wilder BJ: Cholinergic modulation of human P3 event related potentials. Neurology 1987;37: 346-350.

32 Meador KJ, Loring DW, Adams RJ, Platel BR, Davis HC, Hammond EJ: Central cholinergic systems and the auditory P3 evoked potential. Int J Neurosci 1987;33:199-205.

33 Hollander E, Davidson M, Mohs RC, Horvath TB, Davis BM, Zimishlany Z, Davis KL: RS 86 in the treatment of Alzheimer's disease: Cognitive and biological effects. Biol Psychiatry 1987;22:1067-1078.

34 Harrison JB, Buchwald JS, Kaga K, Woolf NJ, Butcher LL: Cat P300 disappears after septal lesions. Electroencephalogr Clin Neurophysiol 1988;69:55-64.

35 Buchwald JS: Animal models of cognitive event-related potentials; in Rohrbaugh JW, Parasuraman R, Johnson R Jr (eds): Event-Related Potentials of the Brain. New York, Oxford University Press, 1990, pp 57-75.

36 Duncan CC, Kaye WH: Effects of clonidine on event-related potential measures of information processing; in Johnson RJ, Rohrbaugh JW, Parasuraman R (eds): Current Trends in Event-Related Potential Research (EEG Suppl 40). Amsterdam, Elsevier, 1987, pp 527-531.
37 Joseph KC, Sitaram N: The effect of clonidine on auditory P300. Psychiatry Res 1989;28: 255-262.

38 Callaway E, Halliday R, Naylor H, Brandeis D: Clonidine and scopalamine: Differences and similarities in how they change human information processing. Prog Neuropsychopharmacol Biol Psychiatry 1991;15:497-502.

39 Buccafusco JJ, Spector S: Mechanism of the antihypertensive action of clonidine on the pressor response to physostigmine. J Pharmacol Exp Ther 1980:212:58-63.

40 Jonkman LM, Kemmer C, Vertaben MN, Koelega HS, Camfferman G, Van der Gaag RJ, Buitelaar JK, Van Engeland H: Effects of methylphenidate on event-related potentials and performance of attention-deficit hyperactivity disorder children in auditory and visual selective attention tasks. Biol Psychiatry 1997; 41:690-702

41 Meador KJ, Loring DW, Lee GP, Taylor HS, Hughes DE, Feldman DS: in vivo probe of central cholinergic systems. J Gerontol 1988;38: 407-414.

42 Halliday R, Naylor H, Callaway E, Yano I, Walton P: What's done can't always be undone: The effects of stimulant drugs and dopamine blockers on information processing; in Jongson R, Parasuraman R, Rohrbaugh JW (eds): Current Trends in Event-Related Potential Research (EEG Suppl 40). Amsterdam, Elsevier, 1987.

43 Aston-Jones G, Foote SL, Bloom FE: Task-relevant late positive component of the auditory event-related potential in monkeys resembles P300 in humans. Science 1984;223:186-188.

44 Pineda JA, Foote SL, Nevile HJ: The effects of locus coeruleus lesions on auditory long-latency event-related potentials in squirrel monkeys. J Neurosci 1989;9:81-93.

45 Pineda JA, Swick D, Foote SL: Noradrenergic and cholinergic influences on the genesis of P3like potentials; in Brunia CHM (ed): EventRelated Potentials of the Brain (EEG Suppl 42). Amsterdam, Elsevier, 1991.

46 Pineda JA: The contribution of parietal-temporal junction to P300 electrogenesis reflects noradrenergic modulation, in preparation.

47 Glover AA, Ghilardi MF, Bodis-Wollner I, Onofrj M: Alterations in event-related potentials (ERPs) of MPTP-treated monkeys. Electroencephalogr Clin Neurophysiol 1988;71: 461-468.

48 Meador KJ: Cholinergic, serotonergic, and GABAergic effects on the ERP. Electroencephalogr Clin Neurophysiol Suppl 1995;44: 151-155.

49 Vanderwolf $\mathrm{CH}$ : Cerebral activity and behaviour: Control by central cholinergic and serotonergic systems. Int Rev Neurobiol 1988;30: 225-340.

50 Vaughan HG Jr, Arezzo JC: The neural basis of event-related potentials; in Picton TW (ed): Human event-related potentials. EEG Handbook. Amsterdam, Elsevier 1988 vol 30, pp 4596.
51 Johnson R Jr: On the neural generators of the P300 component of the event-related potential. Psychophysiology 1993;30:90-97.

52 Halgren E, Squires NK, Wilson CL, Rohrbaugh JW, Babb TL, Crandall PH: Endogenous potentials generated in the human hippocampal formation and amygdala by infrequent events. Science 1980;210:803-805.

53 Okada YC, Kaufman L, Williamsen SJ: The hippocampal formation as a source of the slow endogenous potentials. Electroencephalogr Clin Neurophysiol 1983;55:417-426.

54 Wood CC, McCarthy G, Squires NK, Vaughan HG, Woods DL, McCallum WC: Anatomical and physiological substrates of event-related potentials - two case studies; in Karrer R, Cohen J, Tueting P (eds): Brain and information processing: event related potentials. NY Academy of Science, New York, 1984; pp 681721.

55 Vaughan HG Jr, Ritter W, Simson R: Topographic analysis of auditory event-related potentials; in Kornhuber HH, Deecke L (eds): Progress in Brain Research. Motivation, Motor and Sensory Processes of the Brain: Electrical Potentials, Behaviour and Clinical Use. Amsterdam, Elsevier, 1980, vol 54, pp 279-290.

56 Wood CC, Allison T, Goff WR, Williamson PD, Spencer DD: On the neural origin of P300 in man. Prog Brain Res 1980;54:51-56.

57 Lutzenberger W, Elbert T, Rockstroh B: A brief tutorial on the implications of volume conduction for the interpretation of the EEG. Int $\mathrm{J}$ Psychophysiol 1987;1:81-89.

58 Paller KA, McCarthy G, Roessler E, Allison T, Wood CC: Potentials evoked in human and monkey medial temporal lobe during auditory and visual oddball paradigms. Electroencephalogr Clin Neurophysiol 1992;84:269-279.

59 Johnson R Jr: Developmental evidence for modality-dependent P300 generators: A normative study. Psychophysiology 1989;26:651667

60 Scheffers MK, Johnson R Jr, Ruchkin DS: P300 in patients with unilateral temporal lobectomies: The effects of reduced stimulus quality. Psychophysiology 1991;28:274-284.

61 Stapelton JM, Halgren E: Endogenous potentials evoked in simple cognitive tasks: Depth components and task correlates. Electroencephalogr Clin Neurophysiol 1987;67:44-52.

62 Polich J, Squires LR: P300 from amnestic patients with bilateral hippocampal lesions. Electroencephalogr Clin Neurophysiol 1993;86: 408-417.

63 McCarthy G, Wood CC: Intracranial recordings of endogenous ERPs in humans. Electroencephalogr Clin Neurophysiol Suppl 1989; 39:331-337.

64 Rugg MD, Pickles CD, Potter DD, Roberts CR: Normal P300 following extensive damage to the left medial temporal lobe. J Neurol, Neurosurg, Psychiatry 1991;54: 217-222.

65 Halgren E, Baudena P, Clarke JM, Heit G, Liègeois $\mathrm{C}$, Chauvel $\mathrm{P}$, Musolino A: Intracerebral potentials to rare target and distractor auditory and visual stimuli. I. Superior temporal plane and parietal lobe. Electroencephalogr Clin Neurophysiol 1995;94:191-220. 
66 Halgren E, Baudena P, Clarke JM, Heit G, Marinkovic K, Devaux B, Vignal J-P, Biraben A: Intracerebral potentials to rare target and distractor auditory and visual stimuli. II. Medial, lateral and posterior temporal lobe. Electroencephalogr Clin Neurophysiol 1995;94: 229-250.

67 Kiss I, Dashieff RM, Lordeon P: A parietooccipital generator for P300: Evidence from human intracranial recordings. Int $\mathbf{J}$ Neurosci 1989;49:133-139.

68 Smith ME, Halgren E, Sokolik M, Baudena P, Musolino A, Liègeois-Chauvel C, Chauvel P: The intracranial topography of the P30 eventrelated potential elicited during auditory oddball. Electroencephalogr Clin Neurophysiol 1990;76:235-248.

69 O’Connor TA, Starr A: Intracranial potentials correlated with an event-related potential, P300, in the cat. Brain Res 1985;339:27-38.

70 Yamaguchi S, Knight RT: Anterior and posterior association cortex contributions to the somatosensory P300. J Neurosci. 1991;11:20392054.

71 Verleger R: Event-related potentials and cognition: A critique of the context updating hypothesis and an alternative interpretation of P3. Behav Brain Sci 1988;11:343-427.

72 Ford JM, Sullivan EV, Marsh L, White PM, Lim KO, Pfefferbaum A: The relationship between P300 amplitude and regional grey matter volumes depends upon the attentional system engaged. Electroencephalogr Clin Neurophysiol 1994;90:214-228.
73 McCarley RW, Faux SF, Shenton M, LeMay M, Cane M, Ballinger R, Duffy FH: CT abnormalities in schizophrenia. Arch Gen Psychiatry 1989;46:698-708.

74 Simson R, Vaughan HG, Ritter W: The scalp topography of potentials in auditory and visual discrimination tasks. Electroencephalogr Clin Neurophysiol 1977;42:528-535.

75 Goff WR, Allison T, Vaughan HG: The functional neuroanatomy of event related potentials; in Callaway E, Tueting $\mathrm{P}$, Koslow $\mathrm{SH}$ (eds): Event-related brain potentials in man New York, Academic Press, 1978; pp 1-79.

76 Hegerl U, Frodl-Bauch T: Dipole source analysis of P300 component of the auditory evoked potential: A methodological advance? Psychiatry Res Neuroimaging 1997;74:109-118.

77 Squires NK, Squires KC, Hillyard SA: Two varieties of long-latency positive waves evoked by unpredictable auditory stimuli in man. Electroencephalogr Clin Neurophysiol 1975;83: 387-401.

78 Ruchkin DS, Sutton S, Munson R, Silver K, Macar F: P300 and feedback provided by absence of the stimulus. Psychophysiology 1981; 18:271-282.
79 Ruchkin DS, Sutton S: Positive slow wave and P300: Association and dissociation; in Gaillard AWK, Ritter W (eds): Tutorials in ERP Research: Endogenous Components. Amsterdam, North-Holland, 1983.

80 Donchin E, Tueting P, Ritter W, Kutas M, Heffley $\mathrm{E}$ : On the independence of the $\mathrm{CNV}$ and the P300 components of the human averaged evoked potential. Electroencephalogr Clin Neurophysiol 1975;38:449-469.

81 Rogers RL, Baumann SB, Papanicolaou AC, Bourbon TW, Alagarsamy S, Eisenberg HM: Localization of the P3 sources using magnetoencephalography and magnetic resonance imaging. Electroencephalogr Clin Neurophysiol 1991;79:308-321.

82 Wood CC, McCarthy G: A possible frontal lobe contribution of scalp P300. Soc Neurosci Abstr 1985;11:879-880.

83 Alain C, Richer F, Achim A, Saint-Hilaire JM: Human intracerebral potentials associated with target, novel and omitted auditory stimuli. Brain Topogr 1984;1:237-245.

84 Baudena P, Halgren E, Heit G, Clarke JM: Intracerebral potentials to rare target and distractor auditory and visual stimuli. III. Frontal cortex. Electroencephalogr Clin Neurophysiol 1995;94:251-264.

85 Creutzfeldt OD: Cortex Cerebri. Heidelberg, Springer, 1983.

86 Knight RT: Decreased response to novel stimuli after prefrontal lesions in man. Electroencephalogr Clin Neurophysiol 1994;59:9-20. 